\title{
Biomarker-Guided Risk Assessment for Acute Kidney Injury: Time for Clinical Implementation?
}

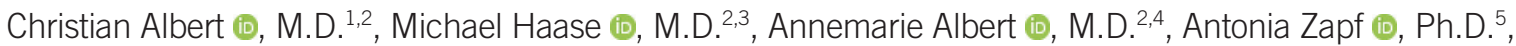 \\ Rüdiger Christian Braun-Dullaeus (10, M.D. ${ }^{1}$, and Anja Haase-Fielitz (10, Pharm.D. ${ }^{6,7,8}$ \\ ${ }^{1}$ Medical Faculty, University Clinic for Cardiology and Angiology, Otto-von-Guericke-University Magdeburg, Magdeburg, Germany; ${ }^{2}$ Diaverum Renal Services, \\ MVZ Potsdam, Potsdam, Germany; ${ }^{3}$ Medical Faculty, Otto-von-Guericke University Magdeburg, Magdeburg, Germany; ${ }^{4}$ Department of Nephrology and \\ Endocrinology, Klinikum Ernst von Bergmann, Potsdam, Germany; ${ }^{5}$ Department of Medical Biometry and Epidemiology, University Medical Center Hamburg- \\ Eppendorf, Germany; ${ }^{6}$ Department of Cardiology, Immanuel Diakonie Bernau, Heart Center Brandenburg, Brandenburg Medical School Theodor Fontane \\ (MHB), Germany; ${ }^{7}$ Institute of Social Medicine and Health Systems Research, Otto-von-Guericke University Magdeburg, Magdeburg, Germany; ${ }^{8}$ Faculty of \\ Health Sciences Brandenburg, Potsdam, Germany
}

Acute kidney injury (AKI) is a common and serious complication in hospitalized patients, which continues to pose a clinical challenge for treating physicians. The most recent Kidney Disease Improving Global Outcomes practice guidelines for AKI have restated the importance of earliest possible detection of AKI and adjusting treatment accordingly. Since the emergence of initial studies examining the use of neutrophil gelatinase-associated lipocalin (NGAL) and cycle arrest biomarkers, tissue inhibitor metalloproteinase-2 (TIMP-2) and insulin-like growth factor-binding protein (IGFBP7), for early diagnosis of AKI, a vast number of studies have investigated the accuracy and additional clinical benefits of these biomarkers. As proposed by the Acute Dialysis Quality Initiative, new AKI diagnostic criteria should equally utilize glomerular function and tubular injury markers for AKI diagnosis. In addition to refining our capabilities in kidney risk prediction with kidney injury biomarkers, structural disorder phenotypes referred to as "preclinical-" and "subclinical AKI" have been described and are increasingly recognized. Additionally, positive biomarker test findings were found to provide prognostic information regardless of an acute decline in renal function (positive serum creatinine criteria). We summarize and discuss the recent findings focusing on two of the most promising and clinically available kidney injury biomarkers, NGAL and cell cycle arrest markers, in the context of AKI phenotypes. Finally, we draw conclusions regarding the clinical implications for kidney risk prediction.

Key Words: Acute kidney injury, AKI phenotypes, Neutrophil gelatinase-associated lipocalin, Subclinical AKI, Preclinical AKI, Kidney biomarker, Serum creatinine, Kidney risk prediction, Cell cycle arrest biomarker
Received: February 28, 2020

Revision received: May 23, 2020

Accepted: August 2, 2020

Corresponding author: Christian Albert, M.D. Medical Faculty, University Clinic for Cardiology and Angiology, Otto-vonGuericke University, Leipziger Straße 44, 39120 Magdeburg, Germany and Diaverum Renal Services, Germany Diaverum MVZ Am Neuen Garten, Am Neuen Garten 11, 14469 Potsdam, Germany

Tel: +49-331-280690

Fax: +49-331-2806932

E-mail: Christian.Albert@Diaverum.com

\section{(c) (1) (8)}

(c) Korean Society for Laboratory Medicine This is an Open Access article distributed under the terms of the Creative Commons Attribution Non-Commercial License (https://creativecommons.org/licenses/by-nc/4.0) which permits unrestricted non-commercial use, distribution, and reproduction in any medium, provided the original work is properly cited.

\section{INTRODUCTION}

Acute kidney injury (AKI) is a serious complication among hospitalized patients with an incremental, stage-dependent worsening prognosis [1]. Common causes of AKI in industrialized countries include sepsis, complex surgical interventions, such as cardiac surgery, cardiogenic shock, and acute decompensated heart failure (AHF) [2]. Acute complications associated with AKI, such as hyperkalemia, renal acidosis, and organ edema, are independent risk factors for patient mortality [3]. The most recent Kidney Disease Improving Global Outcomes (KDIGO) clinical practice guidelines for AKI reemphasized the importance of earliest possible detection of AKI and adjustment of treatment accordingly $[4,5]$. In clinical practice, AKI warning systems can 
automatically report an acute rise in serum creatinine (SCr), as defined in agreed guidelines [4], and when linked to KDIGOrecommended care bundles [4], may contribute to improved patient outcomes [6, 7]. However, such increases in SCr may be delayed by 48-72 hours in an AKI setting. Under these conditions, therapeutic care bundles may be initiated after glomerular function has already declined and potential irreversible organ damage may already be present.

Experimental and clinical studies have underlined the potential and beneficial role of kidney biomarker determination for early assessment of kidney risk. Based on advances in the pathophysiological understanding of AKI and available evidence, the 10th Consensus Conference of the Acute Dialysis Quality Initiative suggested that combining SCr-based AKI definitions with kidney injury biomarkers would provide better precision for AKI course prognostication [8]. Challenging traditional AKI definitions, new diagnostic criteria would include both glomerular function and kidney tubular injury biomarkers equally for AKI diagnosis, while acknowledging that such biomarkers and $\mathrm{SCr}$ (current reference test) concentrations represent different types of kidney impairment, indicating tubular risk/stress/injury and declining filtration function, respectively $[9,10]$.

\section{LIMITATIONS OF SCr}

AKI consensus definitions are based on SCr and urinary output [4]. SCr is universally used as a surrogate parameter of renal function and is reasonably reliable for the classification and monitoring of chronic kidney disease (CKD) under steady state creatinine generation and excretion conditions; however, it may be misleading under conditions of acute decline in glomerular filtration rate (GFR) [11]. Moreover, in patients with reduced muscle mass, SCr may not increase adequately despite a substantial reduction in GFR [12]. Conversely, increases in SCr may not reliably reflect the underlying pathophysiology connected to AKI cell/tissue stress/injury or for example, during so-called prerenal conditions [13]. As SCr is a poor functional marker with limited sensitivity and specificity for accurately estimating rapid changes in GFR [13, 14], it does not indicate tubular stress or consecutive kidney structural damage. Finally, the incidence of SCr-based AKI differs depending on the consensus definition used [15]. Despite these limitations, evaluations of kidney injury biomarker performance are still based on a comparison with $\mathrm{SCr}$ as a diagnostic standard.

\section{NOVEL FUNCTIONAL BIOMARKERS}

Clinical decisions based on reduced GFR may also be greatly affected by the equation used to calculate the estimated GFR (eGFR) [16]. Recently, alternative markers for glomerular filtration, such as cystatin C $[17,18]$ and proenkephalin (PENK), have been evaluated to overcome the shortcomings of $\mathrm{SCr}$ in AKI settings [14].

Cystatin C is a nonglycosylated $13 \mathrm{kDa}$ cysteine protease inhibitor constitutively expressed by all nucleated cells, and this basal expression is unaffected by gender, age, race, muscle mass (unlike SCr), or diet [19]. It is freely filtrated in the glomerulus and completely degraded by proximal tubular cells without being secreted or reabsorbed; therefore, the plasma concentration of cystatin C indirectly reflects the GFR [20]. As a prognostic marker, cystatin $\mathrm{C}$ has been associated with a risk of adverse outcomes in patients following acute coronary syndrome and has shown value in predicting outcomes in patients with AHF [21, 22].

Enkephalins are endogenous opioids commonly produced by the central nervous system. They were also found in other peripheral tissues, such as the heart and kidneys [23]. PENK is a monomeric peptide (approximately $4.5 \mathrm{kDa}$ ) derived from preproenkephalin $\mathrm{A}$, which appears to be freely filtered through the glomerulus and therefore recently suggested as a potential alternative functional biomarker for AKI [24]. PENK has been shown to correlate with GFR in patients with sepsis and $\operatorname{AHF}[25,26]$. Following AHF, PENK additionally provides prognostic information on both mortality and worsening of renal function [25]. Moreover, PENK has emerged as a valuable predictive marker of septic AKI or the need for renal replacement therapy (RRT) in sepsis patients and as a complication of cardiac surgery [14, 25-28].

\section{KIDNEY TUBULAR INJURY BIOMARKERS}

Detection of tissue stress or injury before the onset of SCr-based AKI may be of particular importance for early initiation of precautionary kidney care-bundles. Because of the limitations of $\mathrm{SCr}$, there has been considerable interest in identifying a universal replacement-biomarker for the kidney [29]. However, multiple factors may interact in AKI genesis [30]. In addition to the clinical relevance of cardiosurgical interventions for the development of AKI [31, 32], the ability to determine the timing of potential kidney injury during or after cardiopulmonary bypass is of great advantage for investigating new biomarkers. Cardiac surgery-associated AKI remains an important source of patient mor- 
bidity and mortality, where hemodynamics [33] and the involvement of oxidative stress, hypoxia, inflammation, and metabolism of labile iron metabolites appear to be of particular relevance [34]. Kidney tubular injury biomarkers linked to AKI pathomechanisms enable the detection of renal impairment, not previously detected by routine clinical measurements (e.g., SCr and urine output); this reflects a potential disconnect between SCr-based/ glomerular and tubular renal affection.

Of the early kidney tubular damage or stress biomarkers, robust data are available on the diagnostic and prognostic accuracy of urinary neutrophil gelatinase-associated lipocalin (NGAL) $[35,36]$. NGAL concentrations peak approximately six hours after tubular injury and follow a dose-response curve with respect to injury severity $[37,38]$. NGAL is readily available on clinical laboratory platforms (Table 1) and, compared to other settings $[14,39,40]$, appears to have discriminatory value for predicting adverse kidney-related events after cardiac surgery [41-43]. Both NGAL and hepcidin participate as regulators of tubular iron metabolism [34, 44, 45]. However, the active form of the latter, hepcidin-25, was found to be upregulated in the urine of patients who do not develop AKI after cardiac surgery [46, 47], potentially indicating a nephroprotective ability via its interaction with labile-iron compounds [48].

Renal epithelial cells involved in severe structural tubular injury may undergo G1 cell cycle arrest in ischemic or septic AKI settings, thus providing a potential damage repair option [49].
The products of two G1 cell cycle arrest urinary biomarkers, tissue inhibitor metalloproteinase-2 (TIMP-2) and insulin-like growth factor-binding protein 7 (IGFBP7), have been extensively validated for risk stratification of severe AKI in multidisciplinary care settings $[50,51]$ and have recently been approved for kidney risk assessment by the US Food and Drug Administration [52] (Table 1). Providing high specificity for acute tubular stress, these markers appear to increase rapidly in urine $[53,54]$ and may predict moderate to severe AKI (KDIGO stage 2-3) within 12 hours after biomarker measurement [55].

\section{Validation of the discriminative ability of kidney injury biomarkers for AKI prediction}

Previous methods to evaluate AKI biomarkers were heterogenous, and thus hindered the comparison of findings, potentially limiting the adoption of these markers in clinical practice [56]. The clinical cutoff concentrations of cell cycle arrest markers were derived by Hoste, et al. [57] and subsequently validated for AKI risk stratification in a diverse population of critically ill patients [58].

However, statistical indices and cutoff concentrations specific for NGAL have not been reported in a standardized fashion; in contrast to cell cycle arrest markers [57], the absence of NGAL cutoff concentrations with high sensitivity (intended to identify patients at high risk for AKI [4]) and high specificity, which would enable their adjunct application in clinical decision-making, is a

Table 1. Overview of reviewed biomarkers measurable using clinical laboratory platforms

\begin{tabular}{|c|c|c|c|c|c|}
\hline Biomarker & Analyzer system & Sample material & Test type & Measure range & Manufacturer/licensing \\
\hline NGAL & TRIAGE NGAL TEST & Urine/plasma & Point-of-Care immunoassay & $15-1,300 \mathrm{ng} / \mathrm{mL}$ & $\begin{array}{l}\text { Alere; Biosite Inc., San Diego, } \\
\text { CA, USA }\end{array}$ \\
\hline NGAL & THE NGAL TEST ${ }^{\dagger}$ & Urine/plasma & $\begin{array}{l}\text { Particle-enhanced turbidimetric } \\
\text { immunoassay }\end{array}$ & $25-5,000 \mathrm{ng} / \mathrm{mL}$ & $\begin{array}{l}\text { BIOPORTO, BioPorto } \\
\text { Diagnostics, Hellerup, } \\
\text { Denmark }\end{array}$ \\
\hline [TIMP-2]·[IGFBP7] & ASTUTE140 Analyzer & Urine & $\begin{array}{l}\text { Fluorescence immunoassay, } \\
\text { Point-of-Care Test kit } \\
\text { (NEPHROCHECK Test Kit) }\end{array}$ & $\begin{array}{l}\text { TIMP-2:1.2-225 ng/mL; } \\
\text { IGFBP7: } 20-600 \mathrm{ng} / \mathrm{mL} \\
\text { AKI-RISK finding } \\
0.02-135(\mathrm{ng} / \mathrm{mL})^{2} / 1,000\end{array}$ & $\begin{array}{l}\text { Astute Medical, San Diego, CA, } \\
\text { USA }\end{array}$ \\
\hline [TIMP-2]·[IGFBP7] & $\begin{array}{l}\text { VITROS 3,600 } \\
\text { Immunodiagnostic System } \\
\text { and VITROS 5,600 } \\
\text { Integrated System }\end{array}$ & Urine & $\begin{array}{l}\text { NEPHROCHECK Test Reagent } \\
\text { Pack }\end{array}$ & $\begin{array}{l}\text { TIMP-2:1.2-225 ng/mL; } \\
\text { IGFBP7: } 20-600 \mathrm{ng} / \mathrm{mL} \\
\text { AKI-RISK finding } \\
0.02-135(\mathrm{ng} / \mathrm{mL})^{2} / 1,000\end{array}$ & $\begin{array}{l}\text { Ortho Clinical Diagnostics } \\
\text { Raritan, NJ, USA }\end{array}$ \\
\hline
\end{tabular}

NGAL tests are CE-marked (Conformité Européenne) and available for diagnostic use in Europe. NGAL is currently not FDA-approved for diagnostic use in the United States.

*Using an automated dilution procedure, the test can report values up to $6,000 \mathrm{ng} / \mathrm{mL}$; ${ }^{\dagger}$ Available on a variety of automated clinical chemistry analyzers. Abbreviations: NGAL, neutrophil gelatinase-associated lipocalin; [TIMP-2]·[IGFBP7], tissue inhibitor metalloproteinase-2 (TIMP-2) and insulin-like growth factor-binding protein 7 (IGFBP7). 
major limitation in clinical research and practice. Therefore, determining such clinically applicable cutoff concentrations in patients at risk of AKI appears to be the next important step in the clinical validation of NGAL [59].

The performance of NGAL compared with that of $\mathrm{SCr}$ as a diagnostic standard for AKI has been evaluated in various settings such as pediatric or adult cardiac surgery $[60,61]$, patients in the emergency department [62, 63], or critically ill patients [6466]. In these settings, however, the area under the receiver operating characteristic curve $(A \cup C)$ varied significantly depending on confounding factors such as AKI definition and consideration of the urinary output criterion used to define AKI [15], biomarker sampling timing with respect to AKI diagnosis [67], sample material (such as urine or plasma), and patient population [35, 36, 68].

Such variations and the comparison of biomarkers against $\mathrm{SCr}$ as an imperfect gold-standard may lead to the misconception of another imperfect marker. The definition of "false positive" patients with real tubular injury who do not (yet) demonstrate increased SCr [13] or likewise, attributed "false negatives" without biomarker increase, but with established SCr-based AKI, may mistakenly cast doubt on the sensitivity and specificity of a biomarker [35]. The concept of validating kidney injury biomarkers according to SCr-based AKI-definitions has therefore been legitimately challenged by recent studies [9, 10, 35, 69].

\section{Accuracy of NGAL and [TIMP-2]•[IGFBP7] in predicting SCr-based AKI}

In a recent meta-analysis [35] including 52 prospective observational studies involving 13,040 patients, we investigated separately the predictive performance of urinary and plasma NGAL. An individual-study-data meta-analysis considering several known confounders that may influence diagnostic accuracy of NGAL for the prediction of AKI was performed, involving 26 studies with $>6,650$ patients and 1,520 (23\%) AKI events [35]. AKI was uniformly classified by the RIFLE-classification (Risk, Injury, Failure, Loss of kidney function; and End-stage kidney disease classification [70]). We found that the accuracy of NGAL for predicting severe SCr-AKI was moderate to good (AUC for plasma NGAL 0.802 [0.793-0.811]) irrespective of the meta-analytic approach or consideration of several known confounders [15]. Diagnostic accuracy and cutoff concentrations of urine and plasma NGAL increased with increasing AKI severity [35]; however, the associated likelihood ratios and predictive values failed to reach the desired level of accuracy provided by myocardial troponin in patients with CKD and myocardial infarction [71].
Nevertheless, as highlighted by Kellum and Devarajan [72], even a modestly performing biomarker with an AUC <0.70 [67] may assist in clinical decision making, simply by selecting cutoff concentrations that separate patients into groups of relative risk for AKI.

Although some studies have confirmed that NGAL and [TIMP2]-[IGFBP7] are clinically useful biomarkers for assessing the risk of AKI or acute RRT, increasing evidence suggests a plausible disconnect between SCr-based/glomerular and tubular injury $[10,35,69,73,74]$.

Moreover, NGAL AUC values, classification, and test performance indices (sensitivity, specificity, predictive values) for severe AKI in that meta-analysis [35] were similar to those previously reported for [TIMP-2]-[IGFBP7] [57, 58] (Table 2), providing potential evidence that these findings may also apply to cell cycle arrest markers. In patient cohorts used for determining and validating [TIMP-2]•[IGFBP7] cutoff values (Sapphire and Opal studies [50, 57]), Hoste, et al. [57] reported an AUC of 0.80 (95\% confidence interval [Cl], 0.74-0.84) and 0.79 (95\% $\mathrm{Cl}, 0.69-0.88)$, respectively, for severe AKI. In the Sapphire and Opal studies [50, 57], the sensitivity for the designated "high sensitivity cutoff" $\left(0.3 \mathrm{ng} / \mathrm{mL}^{2} / 1,000\right)$ was $89 \%$ in both studies and the specificity was $50 \%$ and $53 \%$, respectively. For a cutoff of $2.0 \mathrm{ng} / \mathrm{mL}^{2} / 1,000$ (designated as the high specificity cutoff), the sensitivity was $42 \%$ and $44 \%$ and the specificity was $95 \%$ and $90 \%$, respectively. A recent meta-analysis [51] on the diagnostic accuracy of [TIMP-2]-[IGFBP7] for AKI reported a sensitivity of $0.76(95 \% \mathrm{Cl}, 0.69-0.82)$ and specificity of 0.48 (95\% $\mathrm{Cl}, 0.44-0.51$ ) for the $0.3 \mathrm{ng} / \mathrm{mL}^{2} / 1,000$ cutoff within 12 hours of intensive care unit (ICU) admission. The sensitivity and specificity for the $2.0 \mathrm{ng} / \mathrm{mL}^{2} / 1,000$ cutoff were 0.42 (95\% Cl 0.34 0.51 ) and $0.94(95 \% \mathrm{Cl}, 0.92-0.95)$, respectively, and the identified pooled AUC was 0.75 [51].

\section{AKI PHENOTYPES}

\section{Subclinical AKI}

Recently, a group of patients that do not meet the SCr-based definitions of AKI, but exhibit elevated biomarker concentrations (false-positive cases), was described [69], highlighting one of the four scenarios essentially differentiating changes in glomerular filtration function and intrinsic structural tubular kidney injury (Fig. 1).

Such patients were referred to as having "subclinical AKI," emphasizing that this type of kidney injury cannot be detected by conventional consideration of SCr-based AKI definitions [69]. 


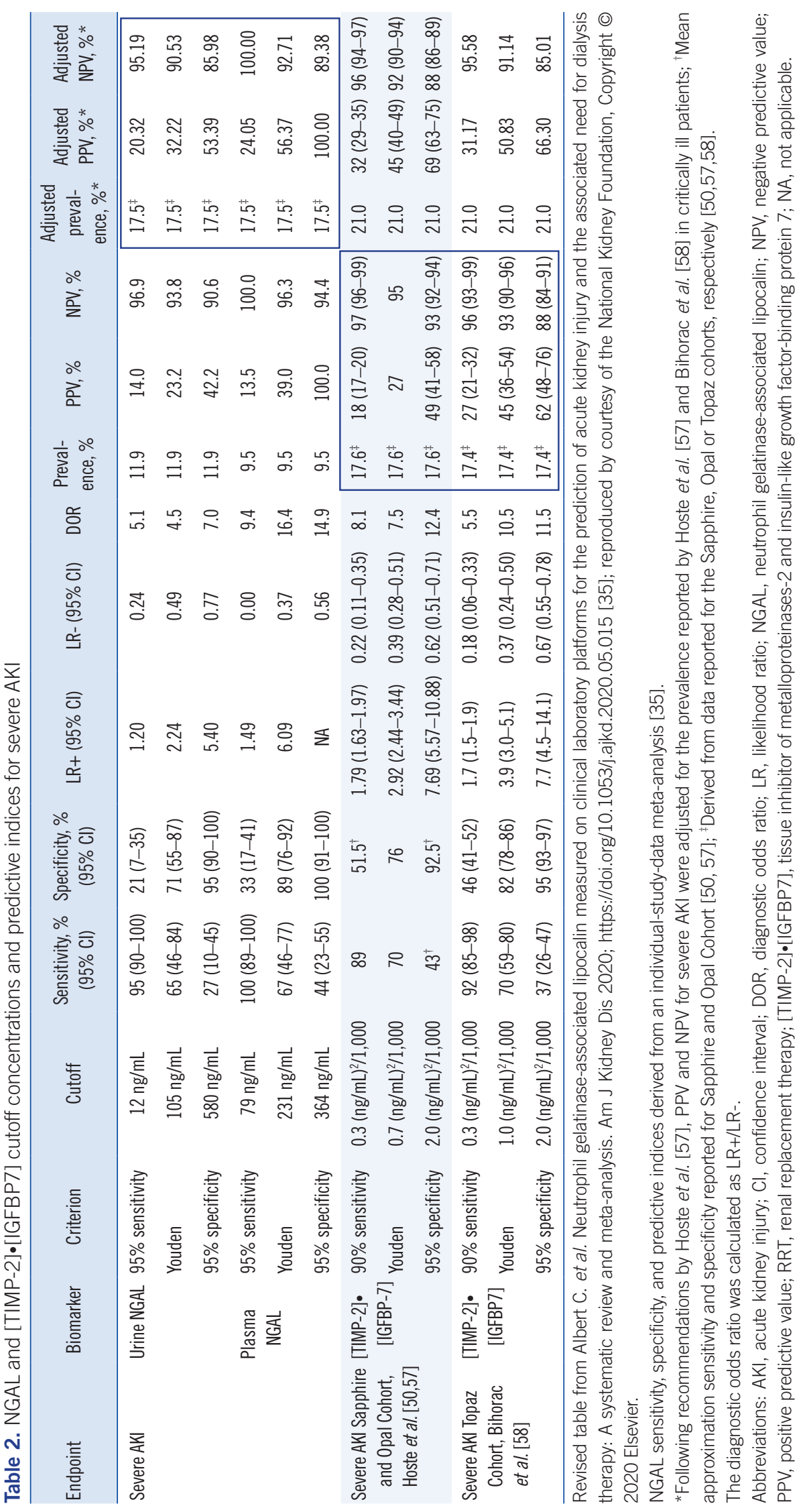




\section{Structural}

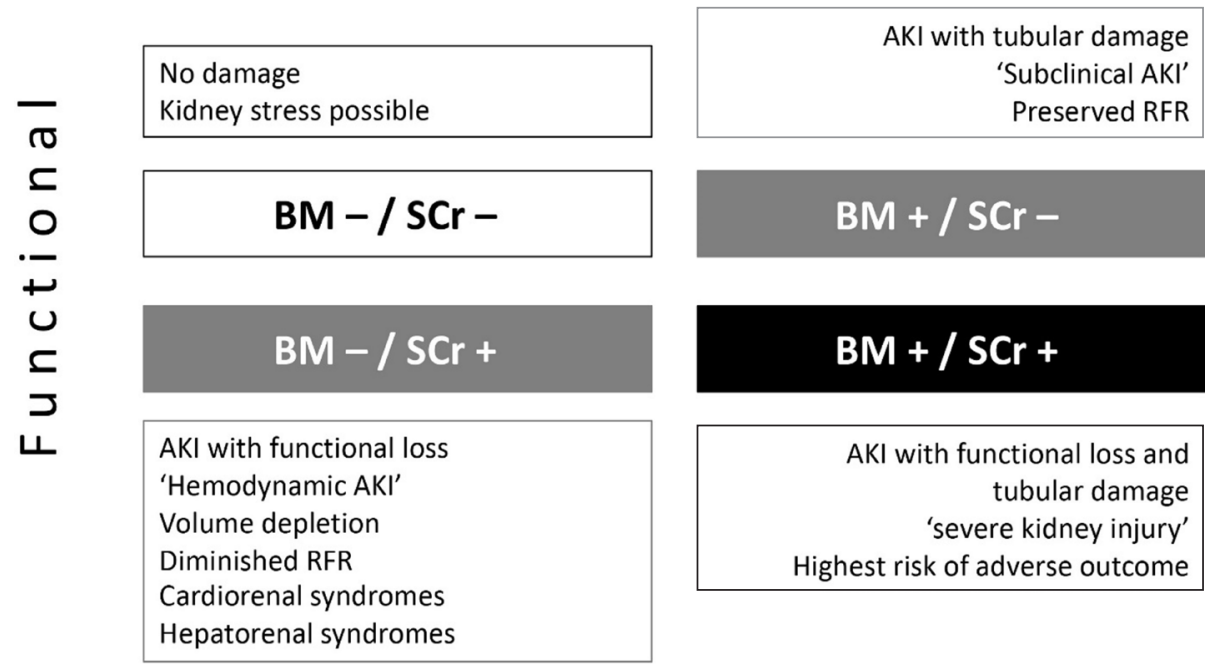

Fig. 1. Entities within the AKI spectrum. AKI phenotypes derived from a $2 \times 2$ table of four scenarios essentially differentiating changes in glomerular filtration function and structural tubular kidney injury.

Abbreviations: AKI, acute kidney injury; BM, biomarker; SCr, serum creatinine; RFR, renal functional reserve.

Subclinical AKI may reflect a consecutive disconnect between $\mathrm{SCr} / \mathrm{glomerular-based} \mathrm{and} \mathrm{tubular} \mathrm{renal} \mathrm{impairment,} \mathrm{which} \mathrm{may}$ occur when tubular injury and the decrease in glomerular filtration in some nephrons are compensated by preserved non-injured nephrons via a limited mechanism known as "renal functional reserve" [75]. Preserved renal functional reserve (and renal mass) may compensate for susceptibility to injury. Even in the presence of sustained tubular stress or acute tubular injury, the damage to the kidney may remain subclinical. In contrast, the susceptibility to such injury progressively increases if renal functional reserve is eventually lost/low and even a mild exposure may become clinically manifest [76] (Fig. 2).

A recent pooled analysis of prospective studies found that patients with subclinical AKI (NGAL-positive/SCr-negative) were at increased risk of subsequent RRT initiation, increased ICU- and in-hospital stay, and most importantly increased mortality [10]. Two subsequent prospective studies confirmed the concept of subclinical AKI by enrolling patients in the emergency department, both reporting on increased risk of RRT initiation or inhospital mortality in biomarker-positive (urinary kidney injury molecule-1 [KIM-1] and urinary or plasma NGAL) patients than in biomarker-negative patients [62, 63].

A concern regarding kidney tubular injury biomarkers in patients undergoing cardiac surgery relates to the fact that they may simply represent inflammation markers rather than kidney injury itself, as they have not been adjusted to the potential degree of inflammation [77].
In a recent prospective study, urinary biomarkers (NGAL, midkine, and interleukin-6), but not C-reactive protein, were identified as independent predictors of AKI after cardiac surgery [73]. We found that urinary kidney biomarkers could identify approximately $60 \%$ more cases with subclinical AKI than conventional SCr-based AKI-status alone. Additionally, the pattern regarding the outcome measures "RRT initiation," "in-hospital mortality," and combination thereof within patient subgroups identified by any urinary kidney injury biomarker as having subclinical AKI, was similar, regardless of which urinary biomarker was used. In a five-year follow-up of the study cohort, impaired long-term survival was found in biomarker-positive versus biomarker-negative patients independent of SCr-based AKI status [75]. This concept was revisited by Xie, et al. [78] who investigated the cell cycle arrest [TIMP-2]·[IGFBP7] markers. However, irrespective of the inflammation status (determined using procalcitonin), there were no significant differences in patients reaching the composite outcome (RRT initiation or mortality) between [TIMP-2]-[IGFBP7]positive/AKI-negative and [TIMP-2]•[IGFBP7]-negative/AKI-negative patients. This finding suggested that the detection of subclinical AKI using cell-cycle arrest markers would be challenging.

A recent study found that 3-11\% of subclinical AKI cases were identified by only one out of three kidney injury biomarkers [73] (NGAL, midkine, or interleukin-6 - single-biomarker positive subclinical AKI). These findings may indicate that different pathophysiological mechanisms of tubular injury may be present, and, on the other hand, patients may be in different phases 


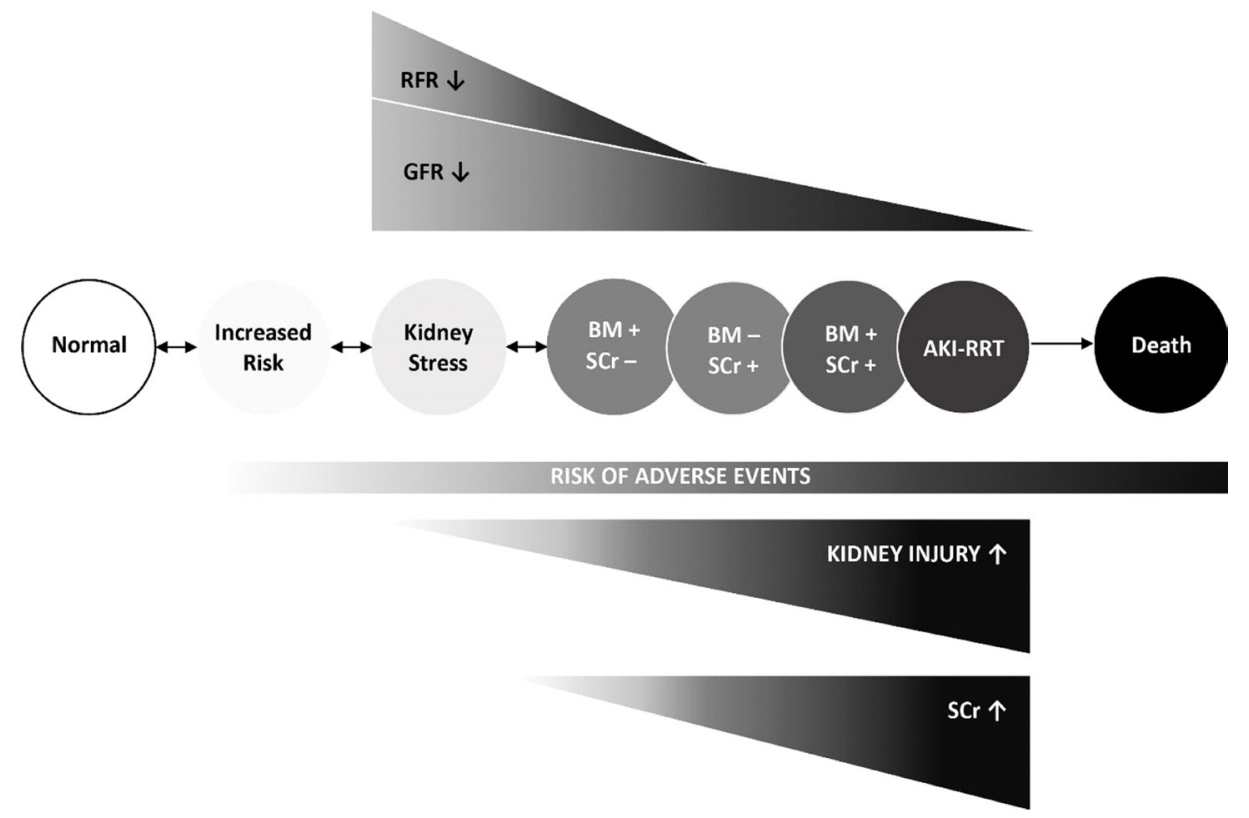

Fig. 2. Revised conceptual model for AKI. White and light grey circles represent antecedents of AKI, i.e. patients at risk with suspected sepsis or those undergoing cardiac surgery. Acute kidney stress is defined as the preinjury phase that may transition into AKI. Sustained kidney stress will mitigate renal functional reserve and eventually transition into any variation of structural and functional kidney impairment $(\mathrm{BM}+/ \mathrm{SCr}-, \mathrm{BM}-/ \mathrm{SCr}+, \mathrm{BM}+/ \mathrm{SCr}+$, and AKI-RRT). Structural kidney injury is indicated by a positive BM (+) finding. Arrows between the circles show potential transitions between AKI stages. AKI requiring RRT or patient death are associated adverse outcomes. Grey variations of the circles for kidney risk, kidney stress, and structural or functional kidney injury reflect increasing risk of adverse events [75, 93].

Abbreviations: AKI, acute kidney injury; SCr, serum creatinine; GFR, glomerular filtration rate; RFR, renal functional reserve; RRT, renal replacement therapy; BM, biomarker.

of tubular injury and repair. Various data have demonstrated that septic AKI has different predominant underlying pathophysiologic processes compared with cardiac surgery-associated AKI $[79,80]$. The existence of single-biomarker positive subclinical AKI needs to be verified and the prognosis of such patients needs to be investigated.

\section{Preclinical AKI}

Considering the naturally delayed diagnostic capability of $\mathrm{SCr}$ and that AKI occurs in a continuum of sustained tubular stress to injury [8, 81] (Fig. 2), another type of kidney biomarker-positivity may be differentiated semantically, physiologically, and clinically from subclinical AKI that is defined without an imminent or subsequent AKI-defining SCr-increase (biomarker-positive/SCr-negative).

This new definition of biomarker-positivity is based on an AKIdefining SCr-increase (reference test) subsequent to biomarkerpositivity (biomarker-positive/SCr-positive). Measurement of such early elevated NGAL concentrations (indicating potential structural injury) within the cutoff concentrations, meta-analyzed at 95\% sensitivity and the cutoff concentration with optimal com- bination of sensitivity and specificity (Youden Index), may indicate a risk of subsequent functional $\mathrm{AKI}$ and suggest intensified kidney observation [82] (former diagnostic "grey-area;" Fig. 3) [35]. We propose that such patients be considered as "preclinically" diagnosed to develop SCr-based AKI, as the biomarker concentration already surpassed a defined threshold [68, 75]. Previous prospective studies focused on patients who fulfilled SCr-based AKI definitions (true-positive for SCr/reference test) subsequent to the measurement of elevated biomarker concentrations [62, 63, 73]. However, considering the variation in renal functional reserve, non-elevated $\mathrm{SCr}$ at the initial biomarker measurement does not preclude GFR decline [83]. In this scenario, we predicted that a change in $\mathrm{SCr}$, defined as loss of glomerular filtration (functional AKI), may have already occurred when the biomarker was measured. Such positive biomarker test findings were found to be prognostically informative regardless of whether renal function acutely declines or not, translating into tubular injury and loss of glomerular filtration or subclinical AKI (false-positive for SCr/reference-test), respectively [73]. 
NGAL risk assessment chart for severe AKI (ng/mL)

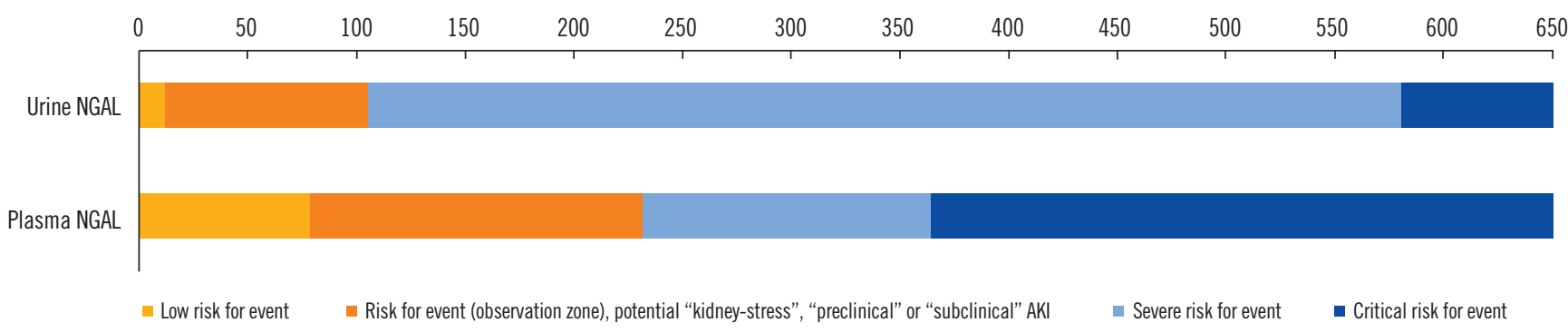

Fig. 3. Risk assessment chart for severe AKI. Consideration of NGAL cutoff concentrations provides the possibility of delineating a diagnostic "grey-zone" in clinical kidney risk assessment into an "Observational Zone" with the risk of kidney stress and preclinical or subclinical AKI. Severe AKI defined as RIFLE AKI stage injury or failure. Derived from data reported in [35].

Abbreviations: AKI, acute kidney injury; NGAL, neutrophil gelatinase-associated lipocalin; RIFLE, risk injury, failure, loss of kidney function, end-stage renal disease classification [70].

\section{Hemodynamic AKI}

The understanding that minor increases in SCr, such as 26.5 $\mu \mathrm{mol} / \mathrm{L}$, may have prognostic value led to the implementation of this criterion in the KDIGO classification of AKI [4]. In a recent meta-analysis [35], out of all patients, we found that SCr-based AKI included $8.0 \%$ of NGAL-negative/RIFLE-positive patients and $20.0 \%$ of NGAL-positive/RIFLE-positive patients. The former are of particular interest as these patients may develop adverse outcomes similar to NGAL-positive/RIFLE-negative (subclinical AKI) patients [62, 63, 73], but their condition is considered as a potentially transient decline in GFR without structural tubular injury (hemodynamic AKI) [84]. However, preexisting or worsening CKD is common in patients hospitalized with $\mathrm{AHF}$ and is associated with a worse prognosis $[85,86]$. A primary goal of the multicenter "AKI NGAL Evaluation of Symptomatic heart failure study" was to examine the ability of NGAL to predict worsening of renal function or need for RRT in patients with AHF treated with diuretics [87]. The occurrence of adverse events increased with increasing NGAL concentrations and decreasing eGFR. Moreover, the predictive ability of NGAL improved with increasing severity of kidney injury, as previously reported [37]. Plasma NGAL was found to be superior to urine NGAL; however, both were inferior to $\mathrm{SCr}$ for the prediction of worsening renal function or adverse in-hospital outcomes [88].

These and previous findings suggest that the pattern and extent of kidney tubular injury associated with the hemodynamic AKI phenotype may be distinctly different from those of other forms of AKI and therefore less biomarker-sensitive without NGAL increase $[89,90]$. This may indicate that the implicated worsening of renal function in the hemodynamic AKI phenotype is potentially reversible depending on available circulatory adjustment capabilities and reflecting physiological volume response.
However, sustained low cardiac output or severe volume depletion may eventually transform into structural kidney injury [91].

\section{Severe cases of AKI}

Although universal screening biomarkers for AKI are needed, there is not much evidence for the clinical usefulness of NGAL or [TIMP-2]-[IGFBP7] as such biomarkers [58, 92]. This is because emerging studies suggest that the discriminative performance of NGAL $[35,37]$ or cell cycle arrest biomarkers $[57,58]$ may be most effective among patients at high risk for severe AKI (stages 2 and 3), whereas application of tests for AKI among lower-risk patients yields suboptimal performance [93]. Severe AKI cases more likely comprise both structural tubular injury and loss or significant reduction in glomerular filtration or oliguria with consecutive increase in SCr (Fig. 2). Owing to its nature and intrinsic properties, NGAL is essentially considered as a marker of structural tubular injury, but not of glomerular filtration such as SCr or excretory function (urine-output) [94]. Multiple studies investigating either perioperative changes in proteinuria [73, 95], NGAL [73, 95, 96], or cell cycle arrest markers [78] have demonstrated that patients with SCr-based AKI and the highest biomarker concentrations were at the highest risk of adverse kidney events such as RRT and mortality.

However, only limited studies have investigated the long-term outcomes of combined biomarker- and SCr-based classifications. These studies found that patients with high urinary concentrations of NGAL $[73,95]$ or the highest concentrations of [TIMP2]- [IGFBP7] [74, 97] and SCr-based AKI demonstrate the worst long-term prognosis compared with patients without SCrbased AKI or positive biomarker findings. Additionally, persisting post-AKI proteinuria is associated with increased risk of kidney disease progression [98]. 


\section{SCr-independent assessment of adverse kidney events}

Previous meta-analyses have attempted to provide biomarker accuracy and cutoff concentrations that may indicate substantial kidney injury subsequently necessitating RRT [36, 99]; however, these were limited by clinical practice variability regarding the timing of RRT initiation [99]. These reports indicate that, in general, RRT cutoff concentrations seem to be higher than those for AKI [36, 99]; however, clinically applicable concentrations (e.g., for NGAL) have yet to be reported, representing an important knowledge gap.

Creatinine-independent risk prediction, including hard clinical outcomes, such as RRT, may be possible using urine and plasma NGAL [100]. Considering the variation of practice regarding RRT initiation and the heterogeneity of the evaluated studies, we suggest that a cutoff range between the optimal combination of sensitivity and specificity (Youden index) up to 95\% specificity may indicate a potential need for RRT. The latter cutoff concentration was identified at approximately $>550 \mathrm{ng} / \mathrm{mL}$ for both urine and plasma NGAL [35].

Basu, et al. [18] found that the combination of NGAL with the alternative glomerular filtration marker, plasma cystatin $\mathrm{C}$, provided superior outcome prediction for severe or persisting AKI after cardiac surgery compared with postoperative changes in SCr. PENK increases progressively with AKI severity according to KDIGO stages and remains highly specific for renal function despite inflammatory reactions, as concentrations remain low in the absence of renal dysfunction in septic patients [26]. Considered as a marker reflecting glomerular filtration, PENK may predict kidney functional deterioration prior to the increase in $\mathrm{SCr}$ [27].

A recent study also demonstrated that PENK levels were associated with adverse events, such as RRT requirement, and shortterm mortality in patients with sepsis and septic shock [101].

\section{BIOMARKER GUIDED RISK-ASSESSMENT AND CLINICAL ADOPTION}

To investigate the added diagnostic benefit of tubular injury biomarker implementation in clinical practice, the ability of these biomarkers to complement established clinical risk prediction models for postoperative adverse kidney events was assessed. Such methodologies may reveal the advantages and disadvantages of new biomarkers in risk prediction for patients with and without the event of interest [102]. However, a candidate biomarker should be able to improve an established clinical reference model to be of diagnostic or prognostic benefit [103]. Pre- vious studies have shown that the predictive ability of a risk prediction model may improve following the addition of candidate biomarkers, such as NGAL and interleukin-6 [79], hepcidin-25 [79, 104], or [TIMP-2]·[IGFBP7] [58, 105]. The combination of kidney injury biomarkers and hepcidin-25, previously described as a biomarker with renal protective ability $[47,65]$, was able to further improve diagnostic discrimination [79]. The latter is of particular interest [79]; higher plasma catalytic iron concentrations were shown to be associated with a significantly greater risk of mortality, as were lower hepcidin concentrations in patients with severe AKI stages requiring RRT [106].

Biomarker-improved risk assessment and derived prognostic value may complement automated electronic alert systems, requiring physicians on service to reassess patient status and initiate therapeutic care bundles where appropriate [107, 108].

However, evidence of the benefits of biomarker-guided risk assessment for AKI and RRT in routine clinical decision making is limited [109, 110]. A recent prospective observational study found that risk prediction for major adverse kidney events or AKI using clinical parameters and information of early NGAL test findings was superior to conventional clinical risk assessment after open heart surgery [109]. The improvements associated with NGAL reporting and assessment are mostly based on improvements in the identification of patients that did not develop adverse events. In a study cohort of 276 patients undergoing cardiac surgery, Meersch, et al. [110] found that compared with standard care, implementation of the KDIGO practice guidelines reduced the occurrence and severity of AKI in high-risk patients identified by [TIMP-2]•[IGFBP7] $>0.3 \mathrm{ng} / \mathrm{mL}^{2} / 1,000$ ("high sensitivity cutoff"). Likewise, using the same cutoff concentration for [TIMP-2]·[IGFBP7], Göcze, et al. [111] identified patients at risk after major abdominal surgery and implemented KDIGO care bundle in the identified patients compared with standard intensive care unit care in the control group. They found reduced AKI severity, postoperative SCr increase, length of ICU stay, and hospital stay in the intensified care group. Göcze, et al. [111] and others [112] also reported cost savings favoring biomarker measurement and appropriate adjustment of treatment.

Specific application of novel functional markers has also emerged. In CKD, estimation of GFR based on cystatin $\mathrm{C}$ may be favorable for specific populations [113] to overcome the shortcomings of SCr [114]. However, the ability of eGFR equations based on either cystatin $\mathrm{C}$ or $\mathrm{SCr}$ to correctly reflect $\mathrm{CKD}$ stages or GFR changes in AKI may vary considerably $[14,115]$ and assessment of cystatin $C$ does not provide additional value for the diagnosis of AKI compared with SCr and the eGFR calcula- 
tion [116].

In line with the suggested uncoupling between kidney injury and loss of renal function, an increase in PENK is well correlated with loss of GFR under septic conditions [117], but may not reflect structural tubular injury [118, 119]. However, such increase in plasma PENK might not be affected by the inflammatory response, as PENK concentrations in septic patients without $\mathrm{AKI}$ are reported within the normal range and therefore might be more specific for the assessment of septic kidney dysfunction [118].

\section{CLINICAL IMPLICATIONS}

It has become apparent that using clinical adjudication in conjunction with routine laboratory parameters may be insufficient under complex acute conditions such as AKI. Novel functional and tubular biomarkers may supplement the diagnostic and prognostic value of $\mathrm{SCr}$ by providing additional pathophysiological information. Such previously disregarded information may be needed to improve risk-prediction and clinical decision making. Therefore, perioperative measurement of NGAL or [TIMP2]-[IGFBP7] has been recently proposed for patients at high risk of cardiac surgery-associated AKI [120]. Compared with SCr, these markers could provide additional value by facilitating earlier identification of patients at risk. The optimum temporal window for urinary and plasma NGAL is approximately 6-24 hours post emergency department presentation [66]. In a recent systematic review, the estimated mean time from NGAL sampling to diagnosis of AKI was 51 hours (SD 28 hours) [35].

A prime example of biomarker-guided risk assessment is how cardiologists validate patients with chest-pain using a plethora of diagnostic tools, such as X-ray, tomography, and blood pressure monitoring, as well as brain-natriuretic peptide and myocardial troponin, which are markers used in rule-in/rule out algorithms [121]. Not surprisingly, lactate dehydrogenase has been abandoned as the gold-standard for validating troponin iterations for the diagnosis of myocardial infarction. However, despite its value in diagnosing AHF [122], studies investigating brain-natriuretic peptide as an objective parameter of AHF severity and more appropriate therapy titration have failed to improve patient clinical outcomes [123].

Does this mean that myocardial troponin is the only remaining successful and clinically applicable biomarker? Unlike cardiologists that use myocardial troponin as a surrogate for myocardial infarction, nephrologists should not consider current kidney tubular injury biomarkers as substitutes for measuring SCr and urine-output (both of which constitute poor reference standards), but rather understand their autonomous utility for predicting patient prognosis and detection of structural kidney injury. Nephrologists and non-nephrologists should acknowledge the limitations of not only SCr but also kidney injury biomarkers [10, 73, 124], interpret their test findings in conjunction with other clinical and diagnostic findings, and pursue appropriate management strategies [110]. The importance of early diagnosis and implication of measurements for preventing or reducing the extent of AKI is emphasized by the fact that both structural AKI and functional AKI are equally associated with the development of CKD and its associated comorbidities $[73,96]$. Future studies should therefore focus on "how" rather than "whether" to use kidney injury biomarkers.

\section{Limitations and possibilities for future studies}

An ideal kidney biomarker should be non-invasive, measurable with a short turn-around time in urine or blood samples at early stages of injury, and highly specific for the affected tissue type [125]. It should have a close pathophysiological association with the type of injury (e.g., inflammatory, ischemic) and indicate the amount of damage-ideally following a dose-effect relationship; finally, it should indicate prognosis [126]. The perfect kidney biomarker should be independent of current AKI-definitions based on $\mathrm{SCr}$, which by itself is a surrogate marker of renal function [13].

In contrast to myocardial troponin, which is released only by impaired myocardial muscle cells, none of the reported kidney biomarkers are entirely specific for AKI. Kidney injury biomarkers and $\mathrm{SCr}$ potentially cross-react with inflammatory response and therefore may have limited value in predicting AKI under systemic conditions such as sepsis [127]. Different biomarkers will reach peak concentrations at different time-points after the initial insult; therefore, interpretation of the findings remains challenging in clinical practice [128]. Nonetheless, we have already come a long way of biomarkers from being measured exclusively and with complex enzyme-linked immunosorbent assays, to measurement using bedside kits with turnaround times of approximately 30 minutes (Table 1 ).

Future studies should therefore focus on injury mechanisms to broaden the knowledge of AKI phenotypes based on their pathophysiology. Refining the understanding of the underlying biological sequence from kidney stress to subsequent subclinical or clinical AKI will potentially open possibilities for therapeutic interventions, applications, or withholding medication and improving patient outcomes. 
The recently proposed NGAL cutoff concentrations need formal validation in endpoint studies, especially the delineation of diagnostic "grey zones" of tubular stress for the detection and diagnosis of subclinical AKI [35]. The development of potential biomarker-guided rule-in and rule-out risk assessment strategies and the application of protocolized biomarker measurements in high-risk groups may eventually improve early clinical risk stratification and the identification of adverse kidney related events [82, 109].

\section{CONCLUSIONS}

Ultimately acknowledging the limitations of SCr will essentially pave way for additional detection and stratification of AKI phenotypes, which are of particular prognostic importance. Novel data confirm the necessity of bivalent risk assessment of kidneyrelated outcomes by equally considering biomarkers and $\mathrm{SCr}$, which should be considered when revising the concept and definition of AKI. Simultaneously, cutoff concentrations are now available for NGAL and cell cycle arrest biomarkers, complementing clinical resources to provide the best possible care for patients at risk.

\section{ACKNOWLEDGEMENTS}

None.

\section{AUTHOR CONTRIBUTIONS}

CA wrote the first draft of the manuscript. All authors participated in drafting and/or revising the paper and provided important intellectual contributions. All the authors have accepted responsibility for the entire content of this manuscript and approved submission.

\section{CONFLICTS OF INTEREST}

CA has received honoraria from Siemens Healthineers. MH has received honoraria from Abbott Diagnostics, Alere, Biosite Inc., Siemens Healthineers, and Baxter. AA has received honoraria from Abbott Diagnostics. All companies are involved in the development and marketing of kidney biomarkers.

\section{RESEARCH FUNDING}

None declared.

\section{ORCID}

Christian Albert $\quad$ https://orcid.org/0000-0002-6956-9962

Michael Haase https://orcid.org/0000-0001-8212-7416

Annemarie Albert https://orcid.org/0000-0002-5611-1506

Antonia Zapf https://orcid.org/0000-0001-5339-2472

Rüdiger C. Braun-Dullaeus

https://orcid.org/0000-0003-3888-6532

Anja Haase-Fielitz https://orcid.org/0000-0001-6881-2249

\section{REFERENCES}

1. Chertow GM, Burdick E, Honour M, Bonventre JV, Bates DW. Acute kidney injury, mortality, length of stay, and costs in hospitalized patients. J Am Soc Nephrol 2005;16:3365-70.

2. Ronco C, Bellomo R, Kellum JA. Acute kidney injury. Lancet 2019; 394:1949-64.

3. Haase-Fielitz A, Ernst M, Lehmanski F, Gleumes J, Blödorn G, Spura A, et al. Treatment, clinical course, and cross-sectoral information transmission in patients with acute-on-chronic kidney injury. Bundesgesundheitsblatt- Gesundheitsforschung- Gesundheitsschutz 2019;62:77381.

4. Kellum JA, Lameire N, Aspelin P, Barsoum RS, Burdmann EA, Goldstein SL, et al. Kidney disease: improving global outcomes (KDIGO) Acute Kidney Injury Work Group. KDIGO clinical practice guideline for acute kidney injury. Kidney Int Suppl 2012;2:1-138.

5. Kashani K, Rosner MH, Haase M, Lewington AJP, O'Donoghue DJ, Wilson FP, et al. Quality improvement goals for acute kidney injury. Clin J Am Soc Nephrol 2019;14:941-53.

6. Haase M, Kribben A, Zidek W, Floege J, Albert C, Isermann B, et al. Electronic alerts for acute kidney injury. Dtsch Arztebl Int 2017;114:1-8.

7. Haase-Fielitz A, Elitok S, Schostak M, Ernst M, Isermann B, Albert C, et al. The effects of intensive versus routine treatment in patients with acute kidney injury. Dtsch Arztebl Int 2020;117:289-96.

8. McCullough PA, Shaw AD, Haase M, Bouchard J, Waikar SS, Siew $E D$, et al. Diagnosis of acute kidney injury using functional and injury biomarkers: workgroup statements from the tenth Acute Dialysis Quality Initiative Consensus Conference. Contrib Nephrol 2013;182:13-29.

9. Huen SC and Parikh CR. Molecular phenotyping of clinical AKI with novel urinary biomarkers. Am J Physiol Renal Physiol 2015;309:F40613.

10. Haase M, Devarajan P, Haase-Fielitz A, Bellomo R, Cruz DN, Wagener $G$, et al. The outcome of neutrophil gelatinase-associated lipocalin-positive subclinical acute kidney injury: a multicenter pooled analysis of prospective studies. J Am Coll Cardiol 2011;57:1752-61.

11. Waikar SS and Bonventre JV. Creatinine kinetics and the definition of acute kidney injury. J Am Soc Nephrol 2009;20:672-9.

12. Thongprayoon C, Cheungpasitporn W, Kashani K. Serum creatinine level, a surrogate of muscle mass, predicts mortality in critically ill patients. J Thorac Dis 2016;8:E305-11.

13. Waikar SS, Betensky RA, Emerson SC, Bonventre JV. Imperfect gold standards for kidney injury biomarker evaluation. J Am Soc Nephrol 2012;23:13-21.

14. Kim H, Hur M, Lee S, Marino R, Magrini L, Cardelli P, et al. Proenkephalin, neutrophil gelatinase-associated lipocalin, and estimated glomerular filtration rates in patients with sepsis. Ann Lab Med 2017;37:388- 
97.

15. Zeng X, McMahon GM, Brunelli SM, Bates DW, Waikar SS. Incidence, outcomes, and comparisons across definitions of AKI in hospitalized individuals. Clin J Am Soc Nephrol 2014;9:12-20.

16. Ji M, Lee YH, Hur M, Kim H, Cho HI, Yang HS, et al. Comparing results of five glomerular filtration rate-estimating equations in the Korean general population: MDRD study, revised Lund-Malmö, and three CKD-EPI equations. Ann Lab Med 2016;36:521-8.

17. Wang X, Lin X, Xie B, Huang R, Yan Y, Liu S, et al. Early serum cystatin C-enhanced risk prediction for acute kidney injury post cardiac surgery: a prospective, observational, cohort study. Biomarkers 2020; 25:20-6.

18. Basu RK, Wong HR, Krawczeski CD, Wheeler DS, Manning PB, Chawla LS, et al. Combining functional and tubular damage biomarkers improves diagnostic precision for acute kidney injury after cardiac surgery. J Am Coll Cardiol 2014;64:2753-62.

19. Stevens LA, Coresh J, Schmid CH, Feldman HI, Froissart M, Kusek J, et al. Estimating GFR using serum cystatin $\mathrm{C}$ alone and in combination with serum creatinine: a pooled analysis of 3,418 individuals with CKD. Am J Kidney Dis 2008;51:395-406.

20. Haase M, Bellomo R, Devarajan P, Ma Q, Bennett MR, Möckel M, et al. Novel biomarkers early predict the severity of acute kidney injury after cardiac surgery in adults. Ann Thorac Surg 2009;88:124-30.

21. Correa S, Morrow DA, Braunwald E, Davies RY, Goodrich EL, Murphy $\mathrm{SA}$, et al. Cystatin C for risk stratification in patients after an acute coronary syndrome. J Am Heart Assoc 2018;7:e009077.

22. Flores-Blanco PJ, Manzano-Fernández S, Pérez-Calvo JI, Pastor-Pérez FJ, Ruiz-Ruiz FJ, Carrasco-Sánchez FJ, et al. Cystatin C-based CKD$\mathrm{EPI}$ equations and $\mathrm{N}$-terminal pro-B-type natriuretic peptide for predicting outcomes in acutely decompensated heart failure. Clin Cardiol 2015;38:106-13.

23. Denning GM, Ackermann LW, Barna TJ, Armstrong JG, Stoll LL, Weintraub NL, et al. Proenkephalin expression and enkephalin release are widely observed in non-neuronal tissues. Peptides 2008;29:83-92.

24. Beunders R, Struck J, Wu AHB, Zarbock A, Di Somma S, Mehta RL, et al. Proenkephalin (PENK) as a novel biomarker for kidney function. J App Lab Med 2017;2:400-12.

25. Ng LL, Squire IB, Jones DJL, Cao TH, Chan DCS, Sandhu JK et al. Proenkephalin, renal dysfunction, and prognosis in patients with acute heart failure: a GREAT network study. J Am Coll Cardiol 2017;69:5669.

26. Caironi P, Latini R, Struck J, Hartmann O, Bergmann A, Bellato V, et al. Circulating proenkephalin, acute kidney injury, and its improvement in patients with severe sepsis or shock. Clin Chem 2018;64:1361-9.

27. Rosenqvist M, Bronton K, Hartmann O, Bergmann A, Struck J, Melander O. Proenkephalin a 119-159 (penKid)-a novel biomarker for acute kidney injury in sepsis: an observational study. BMC Emerg Med 2019;19:75.

28. Mossanen JC, Pracht J, Jansen TU, Buendgens L, Stoppe C, Goetzenich A, et al. Elevated soluble urokinase plasminogen activator receptor and proenkephalin serum levels predict the development of acute kidney injury after cardiac surgery. Int J Mol Sci 2017;18:1662.

29. Haase M, Bellomo R, Albert C, Vanpoucke G, Thomas G, Laroy W, et al. The identification of three novel biomarkers of major adverse kidney events. Biomark Med 2014;8:1207-17.

30. Ostermann M and Liu K. Pathophysiology of AKI. Best Pract Res Clin Anaesthesiol 2017;31:305-14.

31. Chertow GM, Lazarus JM, Christiansen CL, Cook EF, Hammermeister $\mathrm{KE}$, Grover $\mathrm{F}$, et al. Preoperative renal risk stratification. Circulation 1997;95:878-84.
32. Conlon PJ, Stafford-Smith M, White WD, Newman MF, King S, Winn MP, et al. Acute renal failure following cardiac surgery. Nephrol Dial Transplant 1999;14:1158-62.

33. Haase-Fielitz A, Haase M, Bellomo R, Calzavacca P, Spura A, Baraki H, et al. Perioperative hemodynamic instability and fluid overload are associated with increasing acute kidney injury severity and worse outcome after cardiac surgery. Blood Purif 2017;43:298-308.

34. Haase M, Bellomo R, Haase-Fielitz A. Novel biomarkers, oxidative stress, and the role of labile iron toxicity in cardiopulmonary bypassassociated acute kidney injury. J Am Coll Cardiol 2010;55:2024-33.

35. Albert C, Zapf A, Haase M, Röver C, Pickering JW, Albert A et al. Neutrophil gelatinase-associated lipocalin measured on clinical laboratory platforms for the prediction of acute kidney injury and the associated need for dialysis therapy: a systematic review and meta-analysis. Am J Kidney Dis 2020; https://doi.org/10.1053/j.ajkd.2020.05.015

36. Haase M, Bellomo R, Devarajan P, Schlattmann P, Haase-Fielitz A, NGAL Meta-Analysis Investigator Group. Accuracy of neutrophil gelatinase-associated lipocalin (NGAL) in diagnosis and prognosis in acute kidney injury: a systematic review and meta-analysis. Am J Kidney Dis 2009;54:1012-24.

37. Haase-Fielitz A, Bellomo R, Devarajan P, Bennett M, Story D, Matalanis $\mathrm{G}$, et al. The predictive performance of plasma neutrophil gelatinase-associated lipocalin (NGAL) increases with grade of acute kidney injury. Nephrol Dial Transplant 2009;24:3349-54.

38. Mishra J, Dent C, Tarabishi R, Mitsnefes MM, Ma Q, Kelly C, et al. Neutrophil gelatinase-associated lipocalin (NGAL) as a biomarker for acute renal injury after cardiac surgery. Lancet 2005;365:1231-8.

39. Kim SY, Jeong TD, Lee W, Chun S, Sunwoo S, Kim SB, et al. Plasma neutrophil gelatinase-associated lipocalin as a marker of tubular damage in diabetic nephropathy. Ann Lab Med 2018;38:524-9.

40. de Geus HRH, Betjes MG, Schaick Rv, Groeneveld JABJ. Plasma NGAL similarly predicts acute kidney injury in sepsis and nonsepsis. Biomark Med 2013;7:415-21.

41. Pickering JW and Endre ZH. The clinical utility of plasma neutrophil gelatinase-associated lipocalin in acute kidney injury. Blood Purif 2013; 35:295-302.

42. Zhou F, Luo Q, Wang L, Han L. Diagnostic value of neutrophil gelatinase-associated lipocalin for early diagnosis of cardiac surgery-associated acute kidney injury: a meta-analysis. Eur J Cardiothorac Surg 2016; 49:746-55.

43. Ho J, Tangri N, Komenda P, Kaushal A, Sood M, Brar R, et al. Urinary, plasma, and serum biomarkers' utility for predicting acute kidney injury associated with cardiac surgery in adults: a meta-analysis. Am J Kidney Dis 2015;66:993-1005.

44. Nemeth $E$ and Ganz T. The role of hepcidin in iron metabolism. Acta Haematol 2009;122:78-86.

45. Mori K, Lee HT, Rapoport D, Drexler IR, Foster K, Yang J, et al. Endocytic delivery of lipocalin-siderophore-iron complex rescues the kidney from ischemia-reperfusion injury. J Clin Invest 2005;115:610-21.

46. Ho J, Reslerova M, Gali B, Gao A, Bestland J, Rush DN, et al. Urinary hepcidin-25 and risk of acute kidney injury following cardiopulmonary bypass. Clin J Am Soc Nephrol 2011;6:2340-6.

47. Prowle JR, Ostland V, Calzavacca P, Licari E, Ligabo EV, Echeverri JE, et al. Greater increase in urinary hepcidin predicts protection from acute kidney injury after cardiopulmonary bypass. Nephrol Dial Transplant 2012;27:595-602.

48. van Swelm RPL, Wetzels JFM, Verweij VGM, Laarakkers CMM, Pertijs JCLM, van der Wijst J, et al. Renal handling of circulating and renalsynthesized hepcidin and its protective effects against hemoglobin-mediated kidney injury. J Am Soc Nephrol 2016;27:2720-32. 
49. Yang QH, Liu DW, Long Y, Liu HZ, Chai WZ, Wang XT. Acute renal failure during sepsis: potential role of cell cycle regulation. J Infect 2009; 58:459-64.

50. Kashani K, Al-Khafaji A, Ardiles T, Artigas A, Bagshaw SM, Bell M, et al. Discovery and validation of cell cycle arrest biomarkers in human acute kidney injury. Crit Care 2013;17:R25.

51. Song Z, Ma Z, Qu K, Liu S, Niu W, Lin T. Diagnostic prediction of urinary [TIMP-2]×[IGFBP-7] for acute kidney injury: a meta-analysis exploring detection time and cutoff levels. Oncotarget 2017;8:100631-9.

52. Food and Drug Administration Letter to Astute Medical 2014. Available from: http://www.accessdata.fda.gov/cdrh_docs/pdf13/den130031.pdf (Accessed July 11, 2020).

53. Heung M, Ortega LM, Chawla LS, Wunderink RG, Self WH, Koyner JL, et al. Common chronic conditions do not affect performance of cell cycle arrest biomarkers for risk stratification of acute kidney injury. Nephrol Dial Transplant 2016;31:1633-40.

54. Emlet DR, Pastor-Soler N, Marciszyn A, Wen X, Gomez H, Humphries $\mathrm{WH}$ 4th, et al. Insulin-like growth factor binding protein 7 and tissue inhibitor of metalloproteinases-2: differential expression and secretion in human kidney tubule cells. Am J Physiol Renal Physiol 2017;312: F284-96.

55. Hoste E, Bihorac A, Al-Khafaji A, Ortega LM, Ostermann M, Hasse M, et al. Identification and validation of biomarkers of persistent acute kidney injury: the RUBY study. Intensive Care Med 2020;46:943-53.

56. Codorniu A, Lemasle L, Legrand M, Blet A, Mebazaa A, Gayat E. Methods used to assess the performance of biomarkers for the diagnosis of acute kidney injury: a systematic review and meta-analysis. Biomarkers 2018;23:766-72.

57. Hoste EAJ, McCullough PA, Kashani K, Chawla LS, Joannidis M, Shaw $A D$, et al. Derivation and validation of cutoffs for clinical use of cell cycle arrest biomarkers. Nephrol Dial Transplant 2014;29:2054-61.

58. Bihorac A, Chawla LS, Shaw AD, Al-Khafaji A, Davison DL, DeMuth GE, et al. Validation of cell-cycle arrest biomarkers for acute kidney injury using clinical adjudication. Am J Respir Crit Care Med 2014;189: 932-9.

59. Kashani K, Cheungpasitporn W, Ronco C. Biomarkers of acute kidney injury: the pathway from discovery to clinical adoption. Clin Chem Lab Med 2017;55:1074-89.

60. Parikh CR, Coca SG, Thiessen-Philbrook H, Shlipak MG, Koyner JL, Wang Z, et al. Postoperative biomarkers predict acute kidney injury and poor outcomes after adult cardiac surgery. J Am Soc Nephrol 2011; 22:1748-57.

61. Parikh CR, Devarajan P, Zappitelli M, Sint K, Thiessen-Philbrook H, Li S, et al. Postoperative biomarkers predict acute kidney injury and poor outcomes after pediatric cardiac surgery. J Am Soc Nephrol 2011;22: 1737-47.

62. Di Somma S, Magrini L, De Berardinis B, Marino R, Ferri E, Moscatelli $P$, et al. Additive value of blood neutrophil gelatinase- associated lipocalin to clinical judgement in acute kidney injury diagnosis and mortality prediction in patients hospitalized from the emergency department. Crit Care 2013;17:R29.

63. Nickolas TL, Schmidt-Ott KM, Canetta P, Forster C, Singer E, Sise M, et al. Diagnostic and prognostic stratification in the Emergency Department using urinary biomarkers of nephron damage: a multicenter prospective cohort study. J Am Coll Cardiol 2012;59:246-55.

64. Hjortrup PB, Haase N, Treschow F, Møller MH, Perner A. Predictive value of NGAL for use of renal replacement therapy in patients with severe sepsis. Acta Anaesthesiol Scand 2015;59:25-34.

65. Mårtensson J, Glassford NJ, Jones S, Eastwood GM, Young H, Peck L, et al. Urinary neutrophil gelatinase-associated lipocalin to hepcidin ra- tio as a biomarker of acute kidney injury in intensive care unit patients. Minerva Anestesiol 2015;81:1192-200.

66. Ralib AM, Pickering JW, Shaw GM, Than MP, George PM, Endre ZH. The clinical utility window for acute kidney injury biomarkers in the critically ill. Crit Care 2014;18:601.

67. Endre ZH, Pickering JW, Walker RJ, Devarajan P, Edelstein CL, Bonventre JV, et al. Improved performance of urinary biomarkers of acute kidney injury in the critically ill by stratification for injury duration and baseline renal function. Kidney Int 2011;79:1119-30.

68. Haase-Fielitz A, Haase M, Devarajan P. Neutrophil gelatinase-associated lipocalin as a biomarker of acute kidney injury: a critical evaluation of current status. Ann Clin Biochem 2014;51:335-51.

69. Haase M, Kellum JA, Ronco C. Subclinical AKI-an emerging syndrome with important consequences. Nat Rev Nephrol 2012;8:735-9.

70. Bellomo R, Ronco C, Kellum JA, Mehta RL, Palevsky P. Acute Dialysis Quality Initiative workgroup. Acute renal failure-definition, outcome measures, animal models, fluid therapy and information technology needs: the Second International Consensus Conference of the Acute Dialysis Quality Initiative (ADQI) Group. Crit Care 2004;8:R204-12.

71. Twerenbold R, Badertscher P, Boeddinghaus J, Nestelberger T, Wildi K, Puelacher $C$, et al. 0/1-hour triage algorithm for myocardial infarction in patients with renal dysfunction. Circulation 2018;137:436-51.

72. Kellum JA and Devarajan P. What can we expect from biomarkers for acute kidney injury? Biomark Med 2014;8:1239-45.

73. Albert C, Albert A, Kube J, Bellomo R, Wettersten N, Kuppe H, et al. Urinary biomarkers may provide prognostic information for subclinical acute kidney injury after cardiac surgery. J Thorac Cardiovasc Surg 2018; 155:2441-52.

74. Joannidis M, Forni LG, Haase M, Koyner J, Shi J, Kashani K, et al. Use of cell cycle arrest biomarkers in conjunction with classical markers of acute kidney injury. Crit Care Med 2019;47:e820-6.

75. Moledina DG and Parikh CR. Phenotyping of acute kidney injury: beyond serum creatinine. Semin Nephrol 2018;38:3-11.

76. Sharma A, Mucino MJ, Ronco C. Renal functional reserve and renal recovery after acute kidney injury. Nephron Clin Pract 2014;127:94100.

77. Kangasniemi OP, Biancari F, Luukkonen J, Vuorisalo S, Satta J, Pokela $\mathrm{R}$, et al. Preoperative C-reactive protein is predictive of long-term outcome after coronary artery bypass surgery. Eur J Cardiothorac Surg 2006;29:983-5.

78. Xie Y, Ankawi G, Yang B, Garzotto F, Passannante A, Breglia A, et al. Tissue inhibitor metalloproteinase-2 (TIMP-2) •IGF-binding protein-7 (IGFBP-7) levels are associated with adverse outcomes in patients in the intensive care unit with acute kidney injury. Kidney Int 2019;95: 1486-93.

79. Albert C, Haase M, Albert A, Kropf S, Bellomo R, Westphal S, et al. Urinary biomarkers may complement the Cleveland score for prediction of adverse kidney events after cardiac surgery: a pilot study. Ann Lab Med 2020;40:131-41.

80. Herget-Rosenthal S, Poppen D, Hüsing J, Marggraf G, Pietruck F, Jakob HG, et al. Prognostic value of tubular proteinuria and enzymuria in nonoliguric acute tubular necrosis. Clin Chem 2004;50:552-8.

81. Katz $\mathrm{N}$ and Ronco C. Acute kidney stress-a useful term based on evolution in the understanding of acute kidney injury. Crit Care 2016;20:23.

82. de Geus HRH, Ronco C, Haase M, Jacob L, Lewington A, Vincent JL. The cardiac surgery-associated neutrophil gelatinase-associated lipocalin (CSA-NGAL) score: a potential tool to monitor acute tubular damage. J Thorac Cardiovasc Surg 2016;151:1476-81.

83. Vanmassenhove J, Van Biesen W, Vanholder R, Lameire N. Subclinical AKI: ready for primetime in clinical practice? J Nephrol 2019;32:9- 
16.

84. Au V, Feit J, Barasch J, Sladen RN, Wagener G. Urinary neutrophil gelatinase-associated lipocalin (NGAL) distinguishes sustained from transient acute kidney injury after general surgery. Kidney Int Rep 2016;1: 3-9.

85. Damman K, Valente MAE, Voors AA, O'Connor CM, van Veldhuisen DJ, Hillege HL. Renal impairment, worsening renal function, and outcome in patients with heart failure: an updated meta-analysis. Eur Heart J 2014;35:455-69.

86. Heywood JT, Fonarow GC, Costanzo MR, Mathur VS, Wigneswaran JR, Wynne J, et al. High prevalence of renal dysfunction and its impact on outcome in 118,465 patients hospitalized with acute decompensated heart failure: a report from the ADHERE database. J Card Fail 2007; 13:422-30

87. Maisel AS, Wettersten N, van Veldhuisen DJ, Mueller C, Filippatos G, Nowak R, et al. Neutrophil gelatinase-associated lipocalin for acute kidney injury during acute heart failure hospitalizations: the AKINESIS study. J Am Coll Cardiol 2016;68:1420-31.

88. Wettersten N, Horiuchi Y, van Veldhuisen DJ, Mueller C, Filippatos G, Nowak R, et al. Short-term prognostic implications of serum and urine neutrophil gelatinase-associated lipocalin in acute heart failure: findings from the AKINESIS study. Eur J Heart Fail 2020;22:251-63.

89. Dupont M, Shrestha K, Singh D, Awad A, Kovach C, Scarcipino M, et al. Lack of significant renal tubular injury despite acute kidney injury in acute decompensated heart failure. Eur J Heart Fail 2012;14:597-604.

90. Singer E, Elger A, Elitok S, Kettritz R, Nickolas TL, Barasch J, et al. Urinary neutrophil gelatinase-associated lipocalin distinguishes pre-renal from intrinsic renal failure and predicts outcomes. Kidney Int 2011;80: 405-14.

91. Bellomo R, Bagshaw S, Langenberg C, Ronco C. Pre-renal azotemia: a flawed paradigm in critically ill septic patients? Contrib Nephrol 2007; 156:1-9.

92. Vijayan A, Faubel S, Askenazi DJ, Cerda J, Fissell WH, Heung M, et al. Clinical use of the urine biomarker [TIMP-2]x[IGFBP-7] for acute kidney injury risk assessment. Am J Kidney Dis 2016;68:19-28.

93. Bell M, Larsson A, Venge P, Bellomo R, Mårtensson J. Assessment of cell-cycle arrest biomarkers to predict early and delayed acute kidney injury. Dis Markers 2015;2015:158658.

94. Delcroix G, Gillain N, Moonen M, Radermacher L, Damas F, Minon JM, et al. NGAL usefulness in the Intensive Care Unit three hours after cardiac surgery. ISRN Nephrol 2012;2013:865164.

95. Coca SG, Garg AX, Thiessen-Philbrook H, Koyner JL, Patel UD, Krumholz HM, et al. Urinary biomarkers of AKI and mortality 3 years after cardiac surgery. J Am Soc Nephrol 2014;25:1063-71.

96. Singer E, Schrezenmeier EV, Elger A, Seelow ER, Krannich A, Luft FC, et al. Urinary NGAL-positive acute kidney injury and poor long-term outcomes in hospitalized patients. Kidney Int Rep 2016;1:114-24.

97. Koyner JL, Shaw AD, Chawla LS, Hoste EAJ, Bihorac A, Kashani K, et al. Tissue Inhibitor Metalloproteinase-2 (TIMP-2)•IGF-Binding Protein-7 (IGFBP-7) levels are associated with adverse long-term outcomes in patients with AKI. J Am Soc Nephrol 2015;26:1747-54.

98. Hsu CY, Chinchilli VM, Coca S, Devarajan P, Ghahramani N, Go AS, et al. Post-acute kidney injury proteinuria and subsequent kidney disease progression: the Assessment, Serial Evaluation, and Subsequent Sequelae in Acute Kidney Injury (ASSESS-AKI) study. JAMA Intern Med 2020;180:402-10.

99. Klein SJ, Brandtner AK, Lehner GF, Ulmer H, Bagshaw SM, Wiedermann CJ, et al. Biomarkers for prediction of renal replacement therapy in acute kidney injury: a systematic review and meta-analysis. Intensive Care Med 2018;44:323-36.
100. Pickering JW and Endre ZH. Linking injury to outcome in acute kidney injury: a matter of sensitivity. PLoS One 2013;8:e62691.

101. Kim H, Hur M, Struck J, Bergmann A, Di Somma S. Proenkephalin predicts organ failure, renal replacement therapy, and mortality in patients with sepsis. Ann Lab Med 2020;40:466-73.

102. Pickering JW and Endre ZH. New metrics for assessing diagnostic potential of candidate biomarkers. Clin J Am Soc Nephrol 2012;7:135564.

103. Pencina MJ, D’Agostino RB Sr, D’Agostino RB Jr, Vasan RS. Evaluating the added predictive ability of a new marker: from area under the ROC curve to reclassification and beyond. Stat Med 2008;27:157-72.

104. Choi N, Rigatto C, Zappitelli M, Gao A, Christie S, Hiebert B, et al. Urinary Hepcidin-25 is elevated in patients that avoid acute kidney injury following cardiac surgery. Can J Kidney Health Dis 2018;5: 20543581 17744224

105. Levante C, Ferrari F, Manenti C, Husain-Syed F, Scarpa M, Hinna Danesi T et al. Routine adoption of TIMP2 and IGFBP-7 biomarkers in cardiac surgery for early identification of acute kidney injury. Int J Artif Organs 2017;40:714-8.

106. Leaf DE, Rajapurkar M, Lele SS, Mukhopadhyay B, Boerger EAS, Mc Causland FR, et al. Iron, hepcidin, and death in human AKI. J Am Soc Nephrol 2019;30:493-504.

107. Rizo-Topete LM, Rosner MH, Ronco C. Acute kidney injury risk assessment and the Nephrology Rapid Response Team. Blood Purif 2017; 43:82-8.

108. Haase-Fielitz A, Albert C, Haase M. Early warning systems in acute kidney insufficiency. Nephrologe 2017;12:318-22.

109. Albert C, Albert A, Bellomo R, Kropf S, Devarajan P, Westphal S, et al. Urinary neutrophil gelatinase-associated lipocalin-guided risk assessment for major adverse kidney events after open-heart surgery. Biomark Med 2018;12:975-85.

110. Meersch M, Schmidt C, Hoffmeier A, Van Aken H, Wempe C, Gerss J et al. Prevention of cardiac surgery-associated AKI by implementing the KDIGO guidelines in high risk patients identified by biomarkers: the PrevAKI randomized controlled trial. Intensive Care Med 2017;43: 1551-61.

111. Göcze I, Jauch D, Götz M, Kennedy P, Jung B, Zeman F, et al. Biomarker-guided intervention to prevent acute kidney injury after major surgery: the prospective randomized BigpAK study. Ann Surg 2018;267: 1013-20.

112. Parikh A, Rizzo JA, Canetta P, Forster C, Sise M, Maarouf O, et al. Does NGAL reduce costs? A cost analysis of urine NGAL (UNGAL) \& serum creatinine (sCr) for acute kidney injury (AKI) diagnosis. PLoS One 2017; 12:e0178091.

113. Meeusen JW, Rule AD, Voskoboev N, Baumann NA, Lieske JC. Performance of cystatin $\mathrm{C}$ - and creatinine-based estimated glomerular filtration rate equations depends on patient characteristics. Clin Chem 2015;61:1265-72.

114. Ferguson TW, Komenda P, Tangri N. Cystatin C as a biomarker for estimating glomerular filtration rate. Curr Opin Nephrol Hypertens 2015; 24:295-300.

115. Luis-Lima S, Escamilla-Cabrera B, Negrín-Mena N, Estupiñán S, Delgado-Mallén $\mathrm{P}$, Marrero-Miranda $\mathrm{D}$, et al. Chronic kidney disease staging with cystatin $\mathrm{C}$ or creatinine-based formulas: flipping the coin. Nephrol Dial Transplant 2019;34:287-94

116. Bongiovanni C, Magrini L, Salerno G, Gori CS, Cardelli P, Hur M, et al. Serum cystatin $C$ for the diagnosis of acute kidney injury in patients admitted in the emergency department. Dis Markers 2015;2015:416059.

117. Marino R, Struck J, Hartmann O, Maisel AS, Rehfeldt M, Magrini L, et al. Diagnostic and short-term prognostic utility of plasma pro-enkeph- 
Albert C, et al.

Biomarker-guided risk assessment for AKI

ANNALS OF

LABORATORY MEDICINE

alin (pro-ENK) for acute kidney injury in patients admitted with sepsis in the emergency department. J Nephrol 2015;28:717-24.

118. Hollinger A, Wittebole X, François B, Pickkers P, Antonelli M, Gayat E, et al. Proenkephalin A 119-159 (Penkid) is an early biomarker of septic acute kidney injury: the Kidney in Sepsis and Septic Shock (KidSSS) study. Kidney Int Rep 2018;3:1424-33.

119. Doemming S, Simon TP, Humbs A, Martin L, Bruells C, Hartmann O, et al. Pro-enkephalin in plasma of surgical icu-patients with sepsis - a pilot study. Intensive Care Med Exp 2015;3(S1):A256.

120. Nadim MK, Forni LG, Bihorac A, Hobson C, Koyner JL, Shaw A, et al. Cardiac and vascular surgery-associated acute kidney injury: the 20th International Consensus Conference of the ADQI (Acute Disease Quality Initiative) Group. J Am Heart Assoc 2018;7:e008834.

121. Boeddinghaus J, Nestelberger T, Twerenbold R, Wildi K, Badertscher P, Cupa J, et al. Direct comparison of 4 very early rule-out strategies for acute myocardial infarction using high-sensitivity cardiac troponin I. Circulation 2017;135:1597-611.

122. Maisel AS, Krishnaswamy P, Nowak RM, McCord J, Hollander JE, Duc $\mathrm{P}$, et al. Rapid measurement of B-type natriuretic peptide in the emer- gency diagnosis of heart failure. N Engl J Med 2002;347:161-7.

123. Pufulete M, Maishman R, Dabner L, Higgins JPT, Rogers CA, Dayer M, et al. B-type natriuretic peptide-guided therapy for heart failure (HF): a systematic review and meta-analysis of individual participant data (IPD) and aggregate data. Syst Rev 2018;7:112.

124. de Grooth HJ, Parienti JJ, Schetz M. AKI biomarkers are poor discriminants for subsequent need for renal replacement therapy, but do not disqualify them yet. Intensive Care Med 2018;44:1156-8.

125. Devarajan P. NGAL for the detection of acute kidney injury in the emergency room. Biomark Med 2014;8:217-9.

126. Devarajan P and Murray P. Biomarkers in acute kidney injury: are we ready for prime time? Nephron Clin Pract 2014;127:176-9.

127. Doi K, Yuen PST, Eisner C, Hu X, Leelahavanichkul A, Schnermann J, et al. Reduced production of creatinine limits its use as marker of kidney injury in sepsis. J Am Soc Nephrol 2009;20:1217-21.

128. Liangos O, Tighiouart H, Perianayagam MC, Kolyada A, Han WK, Wald $\mathrm{R}$, et al. Comparative analysis of urinary biomarkers for early detection of acute kidney injury following cardiopulmonary bypass. Biomarkers 2009;14:423-31. 